\title{
Direct observations of the effect of fine sediment deposition on the vertical movement of Gammarus pulex (Amphipoda: Gammaridae) during substratum drying
}

\author{
Atish N. Vadher · Jonathan Millett $\cdot$ Paul J. Wood
}

Received: 29 August 2017/Revised: 7 February 2018/Accepted: 14 February 2018/Published online: 26 February 2018

(C) The Author(s) 2018. This article is an open access publication

\begin{abstract}
Benthic macroinvertebrates inhabit the streambed sediments of temporary streams during drying events. Fine sediment $(<2 \mathrm{~mm}$ in diameter $)$ deposition and clogging of interstitial pathways reduces the connectivity between benthic and subsurface habitats, potentially inhibiting macroinvertebrate vertical movements. Direct observations within subsurface sediments are, however, inherently difficult. As a result, confirmation of macroinvertebrate vertical movement, and the effect of fine sediment, is limited. We used laboratory mesocosms containing transparent gravel sized particles $(10-15 \mathrm{~mm})$ to facilitate the direct observation and tracking of vertical movements by Gammarus pulex in response to water level reduction and sedimentation. Seven sediment treatments comprised two fine sediment fractions (small: $0.125-0.5 \mathrm{~mm}$, coarse sand: $0.5-1 \mathrm{~mm}$ ) deposited onto the surface of the substrate, and a control treatment where no fine sediment was applied. We
\end{abstract}

Handling editor: Marcelo S. Moretti

A. N. Vadher $(\bowtie) \cdot$ J. Millett · P. J. Wood

Centre for Hydrological and Ecosystem Sciences,

Department of Geography, Loughborough University,

Loughborough, Leicestershire LE11 3TU, UK

e-mail: A.Vadher@Lboro.ac.uk

\section{A. N. Vadher}

Faculty of Arts, Science and Technology, University of Northampton, Avenue Campus, Northampton NN2 6JD, UK found that G. pulex moved into the subsurface gravel sediments in response to drying, but their ability to remain submerged during water level reduction was impeded by fine sediment deposition. In particular deposition of the coarser sand fraction clogged the sediment surface, limiting vertical movements. Our results highlight the potential effect of sedimentation on G. pulex resistance to drying events in streams.

Keywords Sedimentation - Hyporheic zone · Intermittent rivers - Mesocosm - Burrowing · Invertebrate

\section{Introduction}

Streambed drying as a result of climate variability and anthropogenic pressures on water resources is an increasing global phenomenon (Acuña et al., 2014; Leigh et al., 2016), even in historically perennial systems (Datry et al., 2014; Pyne \& Poff, 2017). As streams dry, flow becomes restricted within the channel, often forming a series of disconnected pools prior to complete drying and desiccation of the channel bed (Boulton, 2003). Habitat conditions typically become increasingly unfavourable for most aquatic organisms during drying events, often resulting in the complete elimination of lotic taxa, causing major changes to macroinvertebrate community structure and composition (Bunn \& Arthington, 2002; 
Bogan et al., 2015; Verdonschot et al., 2015; Leigh et al., 2016).

Many macroinvertebrate populations persist during dry events by employing a range of survival strategies including behavioural adaptations, such as vertical movement into the saturated riverbed sediments (Stubbington, 2012; Vander Vorste et al., 2016a; Vadher et al., 2017), or physiological adaptations to desiccation (Strachan et al., 2015; Stubbington et al., 2016) and declining water quality (van Vliet \& Zwolsman, 2008). Lotic macroinvertebrate taxa have been recorded and observed in the saturated subsurface sediments of drying streams, indicating that they may serve as a habitat where fauna may persist (Hose et al., 2005; Fenoglio et al., 2006), and from which populations may recolonize waterbodies following the resumption of flow (Vander Vorste et al., 2016a). However, confirmation of the vertical movement and the tracking of individuals have been hampered by the inherent difficulties associated with making direct observations within subsurface sediments (Vadher et al., 2017).

Sedimentation and the resulting loss of vertical connectivity between surface and subsurface sediments is considered a major cause of instream degradation globally, and may impede subsurface ecological functioning (Navel et al., 2010; Descloux et al., 2013). Fine sediments (typically referred to as particles < $2 \mathrm{~mm}$ in size; Wood \& Armitage, 1997; Jones et al., 2012) can infiltrate into subsurface sediments limiting the vertical movement of instream fauna (Weigelhofer \& Waringer, 2003; Mathers \& Wood, 2016) through the reduction of porosity and surface-groundwater hydrological exchange (Hartwig $\&$ Borchardt, 2014). There is a widely recognised increase in the volume of fine sediment entering and being deposited in rivers as a result of agricultural practices (Lamba et al., 2015), channel management (Dunbar et al., 2010) and urbanisation (Taylor \& Owens, 2009; Naden et al., 2016). Given the predicted increased frequency of stream drying events (Pyne \& Poff, 2017) there is a need to examine the combined effects of sedimentation and drying on faunal populations. Consequently, a growing number of field experiments have demonstrated the deleterious effects of increased fine sediment content within the subsurface on faunal community structure and function within lotic systems (Richards \& Bacon, 1994; Bo et al., 2007; Larsen et al., 2011; Buendia et al., 2013;
Jones et al., 2015). The direct effects of surface (Navel et al., 2010; Vadher et al., 2015) and subsurface (Mathers et al., 2014) clogging/colmation on the vertical movement of macroinvertebrates has, however, only been characterised and quantified more recently, using ex situ experiments. These have demonstrated that sedimentation has a limiting and deleterious effect on macroinvertebrate vertical movements within subsurface sediments (Navel et al., 2010; Mathers et al., 2014; Vadher et al., 2015).

Previous field (e.g., Descloux et al., 2013) and laboratory investigations (e.g., Mathers et al., 2014) have largely inferred faunal responses to sedimentation by measuring the effect on their final position. This reflects the inherent difficulty of making direct, real-time, observations within subsurface sediments (but see Stumpp \& Hose, 2017). Recent studies using individual organisms in mesocosms filled with transparent sediments have facilitated direct observations of invertebrate movements and stranding within subsurface sediments in response to a reduction in water level and drying (e.g., Stumpp \& Hose, 2013; Vadher et al., 2017). This greatly improves the ability to quantify and qualify movement behaviours in a more precise way.

Gammarus pulex (Linnaeus, 1758) (Amphipoda: Gammaridae) is a benthic amphipod common throughout north-western Europe (Crane, 1994; MacNeil et al., 1997). Where abundant, G. pulex is an ecologically important detritivore-shredder (Navel et al., 2010). Gammarus pulex is also important due to its role as both a predator and prey for fish and other invertebrate species (MacNeil et al., 1997; Kelly et al., 2002, 2006). Gammarus pulex have been reported to migrate into subsurface sediments in response to biotic competition (McGrath et al., 2007), elevated temperatures (Wood et al., 2010) and water level reduction (Vander Vorste et al., 2016b; Vadher et al., 2017). Migration has been observed to depths of up to $2 \mathrm{~m}$ during adverse environmental conditions (Dole-Olivier et al., 1997). These characteristics, alongside the ease of care in the laboratory make G. pulex a useful model organism for studying behavioural response to environmental stress. In this study, we examined experimentally the effect of fine sediment deposition on the vertical movement of G. pulex within transparent subsurface sediments during water level reduction. The aim was to determine the extent to which coarse and fine sand deposition affects the vertical 
movement of G. pulex through subsurface sediments in response to water level reduction. We hypothesised that: (i) declining water levels and substrate drying would result in the stranding of G. pulex individuals which were unable to remain submerged; and (ii) the addition of fine sediment (sedimentation) would reduce the number of $G$. pulex remaining submerged as a result of impairment in the ability of individuals to enter the subsurface.

\section{Materials and methods}

\section{Sediment tank mesocosms}

Experiments were conducted using two transparent sediment tanks constructed using $1 \mathrm{~cm}$ thick clear acrylic panels $(50 \mathrm{~cm}$ length $\times 35 \mathrm{~cm}$ height $\times 5 \mathrm{~cm}$ width) to create an internal volume of $5250 \mathrm{~cm}^{3}$ (Fig. 1). To allow drainage, a $7 \mathrm{~mm}$ hole was made centrally into the base of the tank and a $5 \mathrm{~mm}$ silicone tube inserted. Drainage of water was controlled using a Hoffman clip, providing control of water depth to $1 \mathrm{~mm}$ precision (Fig. 1). To aid observation and water drawdown, five horizontal lines were marked onto the tank every $5 \mathrm{~cm}$ from the base (highest horizontal line at $25 \mathrm{~cm}$ from the base). The tanks were filled with a

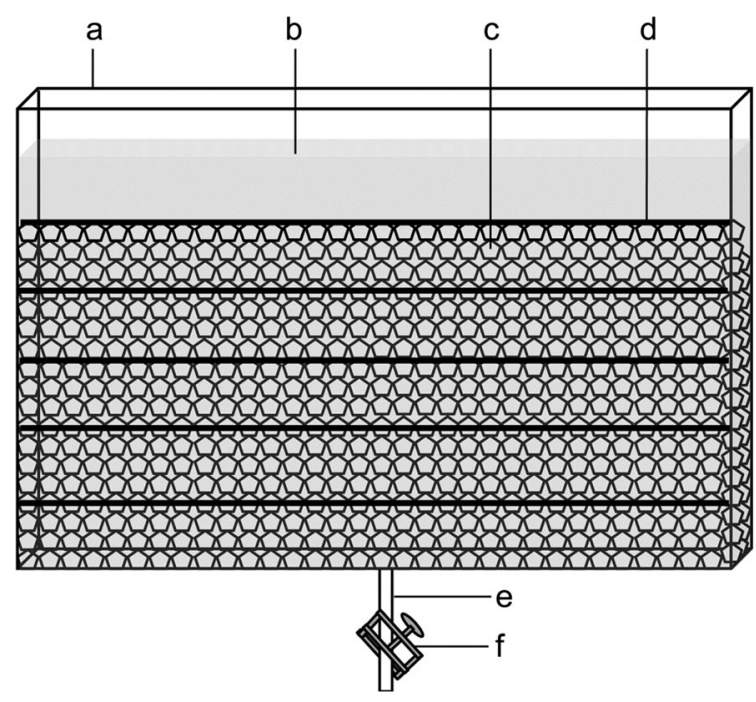

Fig. 1 Sediment tank mesocosm. a acrylic tank $(50 \mathrm{~cm} \times 35 \mathrm{~cm} \times 5 \mathrm{~cm}) ; b$ water level at experiment start ( $5 \mathrm{~cm}$ above the sediment surface); $c 25 \mathrm{~cm}$ of transparent gravel particles $(10-15 \mathrm{~mm}) ; d$ line marked onto the tank at $5 \mathrm{~cm}$ intervals; $e 5 \mathrm{~mm}$ silicone tube; $f$ Hoffman clip transparent gravel sediment substrate to a depth of $25 \mathrm{~cm}$ (Fig. 1) and were held vertically using wooden mounts within an environmental cabinet $(108 \mathrm{~cm} \times 27 \mathrm{~cm} \times 68 \mathrm{~cm})$. The front wall of the cabinet was covered with a black cloth to maintain darkness and provide lighting conditions analogous to the subsurface streambed whilst allowing an observer to inspect the columns inside.

\section{Sediment treatments}

Angular transparent acrylic gravel particles (10-15 mm diameter) were used as the substrate onto which fine sediment treatments were applied. Two sand size fractions (slate based black fluvial sand particles) were used in the experiments, small $(0.125-0.5 \mathrm{~mm})$ and coarse $(0.5-1 \mathrm{~mm})$, to create fine sediment treatments. These size fractions were chosen based on preliminary experiments which indicated that the smaller size fraction infiltrated into the substrate, under gravity, to the bottom of the tanks whilst the coarser sand particles bridged the spaces between the transparent gravel substrate particles, resulting in clogging of the substrate surface (Fig. 2). The interstitial volume within the top $5 \mathrm{~cm}$ of the substrate in each tank was determined by recording the volume of water drained from between the transparent particles (mean \pm SE: tank $1=337 \pm 1 \mathrm{ml}$; tank $2=339 \pm 0.5 \mathrm{ml})$ in the top $5 \mathrm{~cm}$. These interstitial volumes determined the amount of fine sediment required to fill all interstitial spaces within the top $5 \mathrm{~cm}$ of the substrate. In addition to a control sediment treatment which did not contain fine sediment, the two fine sediment sizes were thoroughly mixed in varying proportions of the total interstitial volume (100, 87.5, $75,50,25$ and $12.5 \%$ ) to create seven sediment treatments (Table 1).

\section{Water}

Tap water was pre-treated with AquaSafe ${ }^{\circledR}\left(\right.$ Tetra $^{\circledR}$, Virginia) to neutralise any residual chemicals and cooled to $11^{\circ} \mathrm{C}$ over a $24-\mathrm{h}$ period prior to the commencement of the experiments. Complete oxygen saturation was maintained throughout each experiment using oxygenating tablets (potassium chloride; Supa ${ }^{\circledR}$ ), widely used in domestic aquaria. Immediately prior to the start of each experimental run, water was 

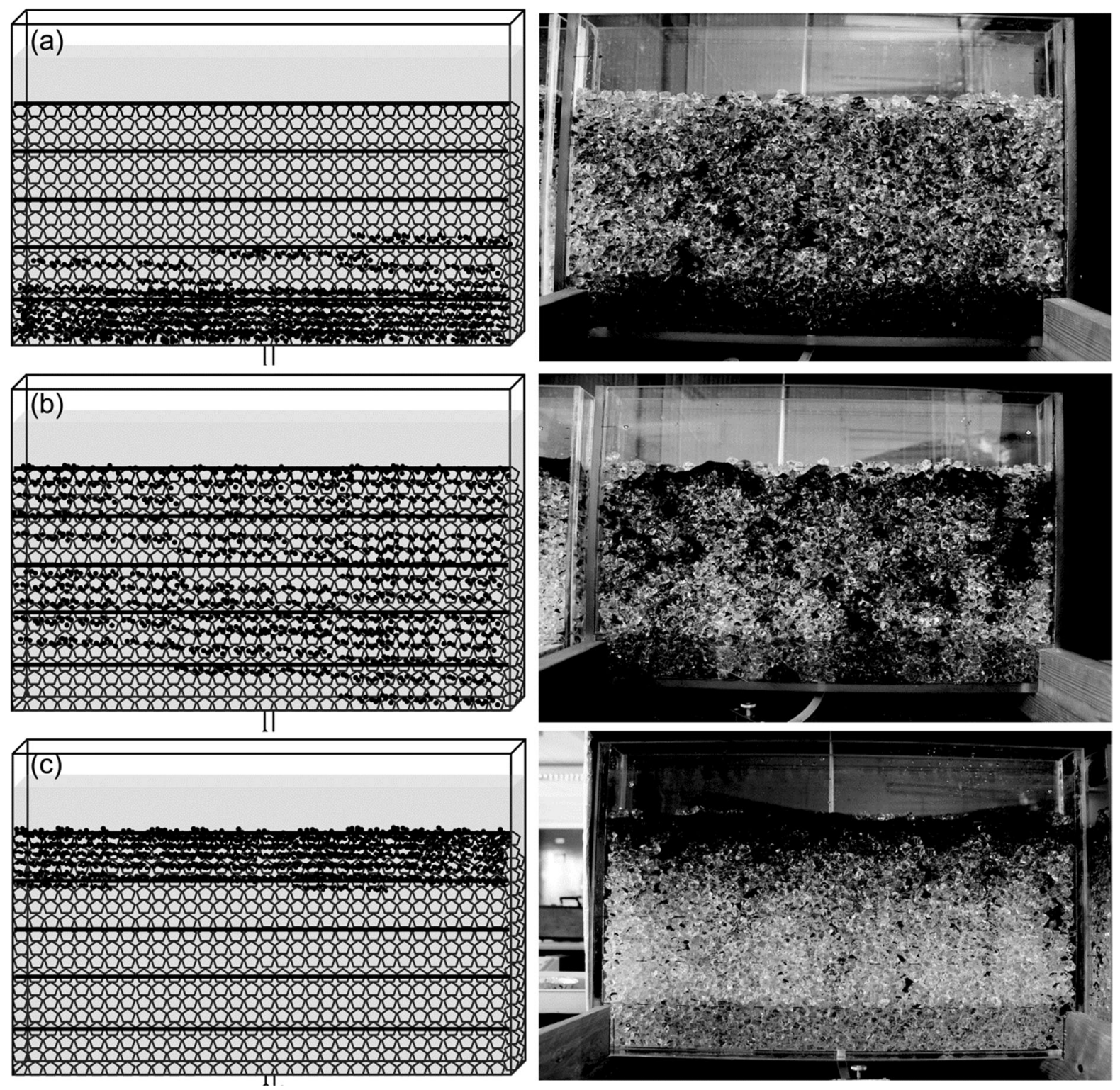

Fig. 2 Fine sediment infiltration through tank mesocosms using mixtures containing small $(0.125 \mathrm{~mm}-0.5 \mathrm{~mm})$ and coarse $(0.5 \mathrm{~mm}-1 \mathrm{~mm})$ fine sediment particles. a $100 \%$ small

fine sediment deposition; b 50\% small and 50\% coarse sediment mixture deposition; c 100\% coarse fine sediment deposition

added to the tanks to $5 \mathrm{~cm}$ above the substrate surface (Fig. 1).

\section{Test organism}

Gammarus pulex were collected using a standard kick net $(900 \mu \mathrm{m}$ mesh, $230 \mathrm{~mm} \times 255 \mathrm{~mm}$ frame, $275 \mathrm{~mm}$ bag depth) from a riffle on Black Brook

$\left(52^{\circ} 45^{\prime} 46.7^{\prime \prime} \mathrm{N} 1^{\circ} 19^{\prime} 19.1^{\prime \prime} \mathrm{W}\right)$ west of the town of Loughborough (Leicestershire, UK). Individuals were tipped from the net onto a $1 \mathrm{~mm}$ aperture sieve and were carefully removed from the sieve surface using tweezers. Individuals with a width $>1 \mathrm{~mm}$ were transported to the laboratory in 5-1 containers of stream water for immediate use in experiments. 
Table 1 The proportion and volume of fine sediments used in each sediment treatment

\begin{tabular}{|c|c|c|c|c|c|}
\hline \multirow[t]{2}{*}{ Treatment } & \multirow[t]{2}{*}{ Fine sediment proportions } & \multicolumn{2}{|c|}{ Volume of small fines $(0.5-1 \mathrm{~mm})(\mathrm{ml})$} & \multicolumn{2}{|c|}{ Volume of coarse fines $(0.125-0.5 \mathrm{~mm})(\mathrm{ml})$} \\
\hline & & Tank 1 & Tank 2 & Tank 1 & Tank 2 \\
\hline 1 & Control & - & - & - & - \\
\hline 2 & $100 \%$ small & 337 & 339 & - & - \\
\hline 3 & $75 \%$ small, $25 \%$ coarse & 253 & 254 & 84 & 85 \\
\hline 4 & $50 \%$ small, $50 \%$ coarse & 169 & 169 & 169 & 169 \\
\hline 5 & $25 \%$ small, $75 \%$ coarse & 84 & 85 & 253 & 254 \\
\hline 6 & $12.5 \%$ small, $87.5 \%$ coarse & 42 & 42 & 295 & 297 \\
\hline 7 & $100 \%$ coarse & - & - & 337 & 339 \\
\hline
\end{tabular}

\section{Experimental procedure}

Sand treatments were poured slowly onto the surface of the transparent gravel substrate through the $5 \mathrm{~cm}$ of surface water and left for 30 min to allow any natural settlement to occur. Ten G. pulex individuals were then introduced into each tank and left to acclimatise for $20 \mathrm{~min}$ prior to the start of the experiments. During preliminary experiments, a $20 \mathrm{~min}$ period was sufficient for exploratory and burrowing activity to subside. To minimise disturbance to organisms during the experiment, observation of the vertical position of G. pulex were made within the dark environmental cabinet using a low level LED light prior to each water level reduction. Water level was reduced in $12.5 \mathrm{~mm}$ increments every 15 min until a depth of $20 \mathrm{~cm}$ below the substrate surface was reached (a total duration of $300 \mathrm{~min}$ until drawdown was complete). A $5 \mathrm{~cm}$ depth of water was retained in each mesocosm at the end of each experiment as a refuge for organisms. Observations began at 'time $=0$ ' ( $5 \mathrm{~cm}$ of surface water) and were made by counting the number of individuals in each $5 \mathrm{~cm}$ horizontal section. When water had been drawn down to $20 \mathrm{~cm}$ below the substrate surface, the number of G. pulex below the waterline (within the $5 \mathrm{~cm}$ refuge) was recorded and experiments terminated. Following the termination of experiments, the contents of each tank was carefully excavated and thoroughly washed to separate the transparent sediment, G. pulex individuals, coarse and small fine sediment particles. Each experimental trial was replicated seven times for each of the seven sediment treatments (including the control treatment; Table 1), providing 49 individual trials. Each trial was observed
21 times following water level reduction (total observations $=1029$ ).

Data analysis

We tested our first hypothesis, that declining water levels and substrate drying would result in some $G$. pulex individuals being unable to remain submerged, and our second hypothesis, that the addition of fine sediment (sedimentation) would result in reduced numbers of G. pulex remaining submerged, using a full-factorial two-way Repeated Measures ANOVA (RMANOVA) analyses. The percentage of G. pulex that remained submerged throughout the experiments were defined as the dependent variable, water depth was defined as the repeated measure (within-subject factor) and sediment treatment was defined as the between subject factor. Mauchly's tests were used to verify the RMANOVA assumption of sphericity and the results of Greenhouse-Geisser tests used when this assumption was violated. We also tested the second hypothesis using a General Linear Model (GLM) to determine differences in the percentage of $G$. pulex that remained submerged at the end of experiments as the dependent factor with the sediment treatment defined as a fixed factor. Post hoc Fisher's Least Significant Difference (LSD) tests were used for both the RMANOVA and GLM models to examine the effect of sediment treatment on the percentage of $G$. pulex that were submerged. The assumptions of homoscedasticity and normality were tested using diagnostic plots. All data conformed to these assumptions so no data transformation was applied. All 
analyses were conducted in IBM SPSS Statistics (version 23, IBM Corporation, New York).

\section{Results}

Effect of water drawdown and fine sediment on vertical movement and stranding of $G$. pulex

The proportion of submerged G. pulex declined as water depth reduced in all sediment treatments, but decreased to a greater extent in treatments comprising higher proportions of coarse sand; there was a significant interaction between water depth and sediment treatment (RMANOVA, Greenhouse-Geisser, $F_{20.992, \quad 146.943}=10.431, \quad P<0.001$; Fig. 3$)$. The effect of water level reduction on the ability of $G$. pulex to move vertically and remain submerged was similar for treatments 1-3, for which between 50-65\% of $G$. pulex were able to remain submerged during the drawdown of water. For treatments 5-6 the percentage of individuals submerged declined quickly for the first $5 \mathrm{~cm}$ of drawdown before a more gradual decrease of individuals remaining submerged was observed.

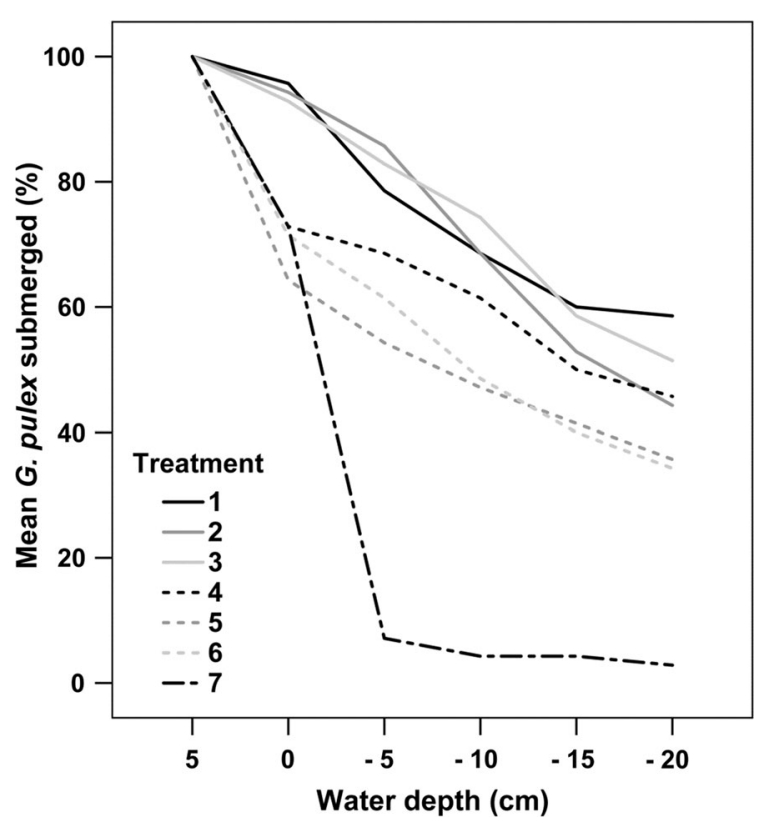

Fig. 3 Sediment treatment and water depth effect on the percentage of submerged Gammarus pulex during experiments. Sediment treatments 1-7 are defined in Table 1. Gammarus pulex burrowing during water depth reduction was similar in treatments $1-3$ and in 5-6 (Fisher's LSD, $P>0.05$ )
Treatment 4 was intermediate between these two other groups. For treatment 7 (100\% coarse sand addition) nearly all G. pulex became stranded following a relatively minor reduction $(10 \mathrm{~cm})$ in water level (Fisher's LSD, $P<0.001$; Fig. 3).

Effect of sediment treatment on the percentage of submerged G. pulex at experiment end

Differences in the percentage of individuals remaining submerged at the end of the experiment were statistically significant for all treatments compared to the control (treatment 1), with the exception of treatment 3 (Table 2). Sediment treatments comprising greater proportions of coarser sand particles reduced the percentage of $G$. pulex submerged at the end of experiments (GLM, $F_{6}, 42=17.061, \quad P<0.001$; Fig. 4), although fewer G. pulex remained submerged at the end of experiments in treatment 2 compared to treatment 3 (Fig. 4). A markedly reduced proportion of G. pulex $(2.9 \% \pm 4.4 \% \mathrm{SE})$ remained submerged at the end of experiments for sediment treatment 7 (100\% coarse sand addition) compared to all other treatments 1-6 (Table 2; Fig. 4).

\section{Discussion}

Some G. pulex individuals were unable to remain submerged during dewatering, supporting our first hypothesis. These results also support the observations of Stumpp \& Hose (2013) and Vadher et al. (2017) that reducing water level in artificial mesocosm experiments resulted in the stranding of individual invertebrates within subsurface sediments. Therefore, water level reduction as an environmental stressor may negatively affect faunal populations within the subsurface sediments. In this laboratory study, water quality parameters were kept relatively stable compared to the changes in water quality that occurs during the natural drying of streams (Boulton \& Lake, 2008). When combined with deteriorating water quality in natural streams, the effects of water level reduction on mortality may be significantly greater in temporary streams (Lake, 2003; Chadd et al., 2017) than those recorded in this study.

A number of studies have inferred that subsurface clogging by fine sediment reduces the potential for vertical movement by invertebrates within subsurface 
Table 2 Fisher's least significant difference (LSD) post hoc pairwise comparison of Gammarus pulex burrowing at the end of experiments in treatments 1-7 (see Table 1)

\begin{tabular}{|c|c|c|c|c|c|c|c|}
\hline \multirow[t]{2}{*}{ Treatment } & \multicolumn{7}{|c|}{ Post hoc Fisher's (LSD) tests } \\
\hline & 1 & 2 & 3 & 4 & 5 & 6 & 7 \\
\hline 1 & & 0.026 & 0.254 & 0.043 & 0.001 & $<\mathbf{0 . 0 0 1}$ & $<0.001$ \\
\hline 2 & & & 0.254 & 0.818 & 0.172 & 0.113 & $<0.001$ \\
\hline 3 & & & & 0.360 & 0.015 & 0.008 & $<0.001$ \\
\hline 4 & & & & & 0.113 & 0.071 & $<0.001$ \\
\hline 5 & & & & & & 0.818 & $<0.001$ \\
\hline 6 & & & & & & & $<0.001$ \\
\hline 7 & & & & & & & \\
\hline
\end{tabular}

Significant differences in $G$. pulex survivorship $(P \leq 0.05)$ between treatments are emboldened

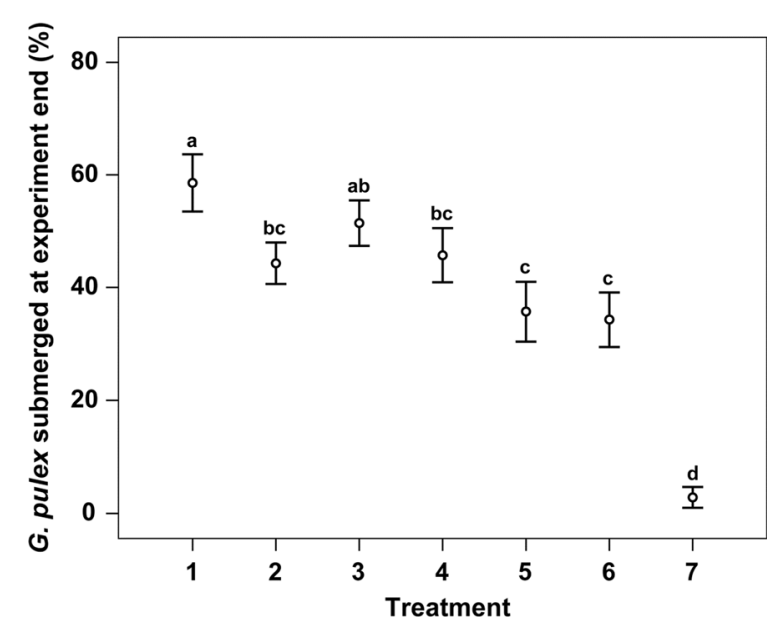

Fig. 4 Mean percentage of Gammarus pulex submerged $( \pm 1$ SE) in sediment treatments at the end of experiments. Treatments 1-7 are defined in Table 1. Treatments with the same letter $(a-d)$ indicate no statistically significant difference (Table 2)

riverbed sediments (e.g., Descloux et al., 2013; Weigelhofer \& Waringer, 2003), but none have previously directly observed these effects in situ. The use of transparent sediments within mesocosms has the potential to enhance understanding of faunal responses to drying in temporary streams, for example, Vadher et al. (2017) demonstrated a gradient of vertical movements through sediments due to different sediment characteristics. Without the use of transparent sediments only binary, presence/absence confirmation would have been possible. As a result, we were able to directly observe how decreased porosity, as a result of sedimentation, reduced the ability of G. pulex to migrate vertically and remain submerged. Gammarus pulex individuals actively moved through subsurface sediments to depths of up to $25 \mathrm{~cm}$ below the sediment surface in response to drying (Vadher et al., 2017). Therefore, this study shows how the extent of vertical movements made by G. pulex in response to surface water loss and drawdown into the subsurface was impeded by sedimentation. In other research, G.pulex has been reported to migrate up to $2 \mathrm{~m}$ vertically in gravel substrates in response to spates (Dole-Olivier et al., 1997) and its ability to maintain populations in hypogean habitats (e.g., Wood et al., 2008) suggests it is able to migrate vertically relatively easily where appropriate habitat and pathways exist.

We found support for our second hypothesis, that the addition of fine sediment (sedimentation) would result in reduced numbers of G. pulex remaining submerged because the ability of individuals to enter the subsurface was impaired. This reflects the high clogging potential of $0.5-1 \mathrm{~mm}$ compared to $0.125-0.5 \mathrm{~mm}$ particles and the ability of larger particles to bridge the interstitial spaces between grains, blocking pathways within the subsurface and reducing sediment porosity/permeability (Boulton et al., 1998; Bo et al., 2007; Vadher et al., 2015). The high clogging potential of the $0.5-1 \mathrm{~mm}$ particles was clearly exhibited in this study as this size fraction completely clogged the surface of mesocosms (bridging the majority of surface interstitial pathways) forming a physical barrier (Gibson et al., 2009) through which G. pulex could not penetrate. The deposition of fine sediment particles $(<2 \mathrm{~mm})$ within riverbeds has 
been previously reported to reduce the vertical movement of macroinvertebrates into subsurface sediments (Richards \& Bacon, 1994; Mathers et al., 2017) and our data demonstrate that these responses are due to the impairment and limitation of the ability of the individuals to move through the substrate. Our results showed a marked stepped/threshold effect of fine sediment on the vertical movement of $G$. pulex between treatment $6(12.5 \%$ small and $87.5 \%$ coarse fine sediment) and treatment $7(100 \%$ coarse fine sediment) which indicates that particle size and the heterogeneity of deposited sediments strongly influenced the ability of individual invertebrate to access the subsurface interstitial habitat.

The extent to which fine sediment and sediment composition affect individual species has been reported to be species-specific (Descloux et al., 2013; Vadher et al., 2017). For example, Descloux et al. (2013) reported a linear decline in macroinvertebrate abundance of species with increasing fine sediment within streambeds with the exception of the ephemeropterans Caenis spp. and Heptageniidae; which displayed an exponential reduction and were completely absent when fine sediment content exceeded 30 and 50\%, respectively. However, while the physical effects of fine sediment on benthic habitat and organisms have been widely recognised (Richards \& Bacon, 1994; Descloux et al., 2013), it is also important to acknowledge the effects that fine sediment deposition has on interstitial flow and the transport of nutrients and dissolved oxygen through subsurface habitats (Olsen \& Townsend, 2003). However, some taxa actively utilise fine sediments as a habitat (e.g., tubificid worms and Chironomidae) and in some instances construct galleries creating hyporheic flow paths and increasing connectivity (Nogaro et al., 2006, 2008). Therefore, further species-specific experiments are needed to quantify the effect of sedimentation on macroinvertebrate fauna.

This study has demonstrated that sedimentation affects $G$. pulex movement and stranding within subsurface habitats. Therefore, the vertical movement responses to sedimentation reported here will likely impact community resistance and resilience to drying as sedimentation reduces the subsurface refuge potential. We therefore highlight the need for effective refuge management through the enhancement of streambed porosity. Such management strategies should include measures to reduce fine sediment inputs into streams using sediment detention ponds/ wetlands and planting riparian vegetation to stabilise river banks (Verstraeten \& Poesen, 2000; Hughes, 2016). Where high river flows are insufficient in flushing fine sediment from streambeds, management techniques such as gravel jetting (Bašić et al., 2017), replenishing depleted coarser grained sediments (Merz \& Ochikubo Chan, 2005; McManamay et al., 2010) and the use of instream structures to enhance hydraulic efficiency to transport fine sediments (Palm et al., 2007; Michel et al., 2014) should be considered.

In conclusion, our study highlights the importance of streambed permeability and fine sediment to allow for the vertical movements of macroinvertebrates during drying events. We particularly highlight the need to quantify the effect of deposited fine sediment composition on faunal community structure within temporary streams. With the frequency of drying events in streams increasing as a result of climate change (Ledger \& Milner, 2015; Pyne \& Poff, 2017) and anthropogenic pressure on water resources (Datry et al., 2014) alongside fine sediment increasing in streams (Lamba et al., 2015; Naden et al., 2016), mesocosm experiments may prove particularly useful in quantify the effects of multiple stressors on ecosystem structure and functioning. Future research should therefore consider approaches which combine field and laboratory/mesocosm-based observations to facilitate greater understanding of streambed drying processes.

Acknowledgements Atish N. Vadher gratefully acknowledges Loughborough University, School of Social, Political and Geographical Sciences studentship for funding this work. We thank Richard Harland for the construction of the mesocosms. We also thank Associate Editor Marcelo Moretti and two anonymous referees, whose suggestions have resulted in an improved manuscript.

Open Access This article is distributed under the terms of the Creative Commons Attribution 4.0 International License (http:// creativecommons.org/licenses/by/4.0/), which permits unrestricted use, distribution, and reproduction in any medium, provided you give appropriate credit to the original author(s) and the source, provide a link to the Creative Commons license, and indicate if changes were made.

\section{References}

Acuña, V., T. Datry, J. Marshall, D. Barceló, C. N. Dahm, A. Ginebreda, G. McGregor, S. Sabater, K. Tockner \& M. 
A. Palmer, 2014. Why should we care about temporary waterways? Science 34: 1080-1081.

Bašić, T., J. R. Britton, S. P. Rice \& A. G. Pledger, 2017. Impacts of gravel jetting on the composition of fish spawning substrates: implications for river restoration and fisheries management. Ecological Engineering 107: 71-81.

Bo, T., S. Fenoglio, G. Malacarne, M. Pessino \& F. Sgariboldi, 2007. Effects of clogging on stream macroinvertebrates: an experimental approach. Limnologica 37: 186-192.

Bogan, M. T., K. S. Boersma \& D. A. Lytle, 2015. Resistance and resilience of invertebrate communities to seasonal and supraseasonal drought in arid-land headwater streams. Freshwater Biology 60: 2547-2558.

Boulton, A. J., 2003. Parallels and contrasts in the effects of drought on stream macroinvertebrate assemblages. Freshwater Biology 48: 1173-1185.

Boulton, A. J. \& P. S. Lake, 2008. Effects of drought on stream insects and its ecological consequences. In J. Lancaster \& R. A. Briers (eds), Aquatic Insects. Challenges to Populations. CABI, Wallingford: 81-102.

Boulton, A. J., S. Findlay, P. Marmonier, E. H. Stanley \& H. M. Valett, 1998. The functional significance of the hyporheic zone in streams and rivers. Annual Review of Ecology, Evolution and Systematics 29: 59-81.

Buendia, C., C. N. Gibbins, D. Vericat, R. J. Batalla \& A. Douglas, 2013. Detecting the structural and functional impacts of fine sediment on stream invertebrates. Ecological Indicators 25: 184-196.

Bunn, S. E. \& A. H. Arthington, 2002. Basic principles and ecological consequences of altered flow regimes for aquatic biodiversity. Environmental Management 30: 492-507.

Chadd, R. P., J. A. England, D. Constable, M. J. Dunbar, C. A. Extence, D. J. Leeming, J. A. Murray-Bligh \& P. J. Wood, 2017. An index to track the ecological effects of drought development and recovery on riverine invertebrate communities. Ecological Indicators 82: 344-356.

Crane, M., 1994. Population characteristics of Gammarus pulex (L.) from five English streams. Hydrobiologia 281: 91-100.

Datry, T., S. T. Larned \& K. Tockner, 2014. Intermittent rivers: a challenge for freshwater ecology. Bioscience 64: 229-235.

Descloux, S., T. Datry \& P. Marmonier, 2013. Benthic and hyporheic invertebrate assemblages along a gradient of increasing streambed colmation by fine sediment. Aquatic Sciences 75: 493-507.

Dole-Olivier, M. J., P. Marmonier \& J. L. Beffy, 1997. Response of invertebrates to lotic disturbance: is the hyporheic zone a patchy refugium? Freshwater Biology 37: 257-276.

Dunbar, M. J., M. Warren, C. Extence, L. Baker, D. Cadman, D. J. Mould, J. Hall \& R. Chadd, 2010. Interaction between macroinvertebrates, discharge and physical habitat in upland rivers. Aquatic Conservation 20: 31-44.

Fenoglio, S., T. Bo \& G. Bosi, 2006. Deep interstitial habitat as a refuge for Agabus paludosus (Fabricius) (Coleoptera: Dytiscidae) during summer droughts. Coleopterists Bulletin 60: 37-41.

Gibson, S., D. Abraham, R. Heath \& D. Schoellhamer, 2009. Vertical gradational variability of fines deposited in a gravel framework. Sedimentology 56: 661-676.
Hartwig, M. \& D. Borchardt, 2014. Alteration of key hyporheic functions through biological and physical clogging along a nutrient and fine-sediment gradient. Ecohydrology 8: 961-975.

Hose, G. C., P. Jones \& R. P. Lim, 2005. Hyporheic macroinvertebrates in riffle and pool areas of temporary streams in south eastern Australia. Hydrobiologia 532: 81-90.

Hughes, A. O., 2016. Riparian management and stream bank erosion in New Zealand. New Zealand Journal of Marine and Freshwater Research 50: 277-290.

Jones, I., I. Growns, A. Arnold, S. McCall \& M. Bowes, 2015. The effects of increased flow and fine sediment on hyporheic invertebrates and nutrients in stream mesocosms. Freshwater Biology 60: 813-826.

Jones, J. I., J. F. Murphy, A. L. Collins, D. A. Sear, P. S. Naden \& P. D. Armitage, 2012. The impact of fine sediment on macro-invertebrates. River Research and Applications 28: 1055-1071.

Kelly, D. W., J. T. A. Dick \& W. I. Montgomery, 2002. The functional role of Gammarus (Crustacea: Amphipoda): shredders, predators, or both? Hydrobiologia 485: 199-203.

Kelly, D. W., R. J. Bailey, C. MacNeil, J. T. A. Dick \& R. A. McDonald, 2006. Invasion by the amphipod Gammarus pulex alters community composition of native freshwater macroinvertebrates. Diversity and Distributions 12: 525-534.

Lake, P. S., 2003. Ecological effects of perturbation by drought in flowing waters. Freshwater Biology 48: 1161-1172.

Lamba, J., A. M. Thompson, K. G. Karthikeyan \& F. A. Fitzpatrick, 2015. Sources of fine sediment stored in agricultural lowland streams, Midwest, USA. Geomorphology 236: 44-53.

Larsen, S., G. Pace \& S. J. Ormerod, 2011. Experimental effects of sediment deposition on the structure and function of macroinvertebrate assemblages in temperate streams. River Research and Applications 27: 257-267.

Ledger, M. E. \& A. M. Milner, 2015. Extreme events in running waters. Freshwater Biology 60: 2455-2460.

Leigh, C., N. Bonada, A. J. Boulton, B. Hugueny, S. T. Larned, R. Vander Vorste \& T. Datry, 2016. Invertebrate assemblage responses and the dual roles of resistance and resilience to drying in intermittent rivers. Aquatic Sciences 78: 291-301.

MacNeil, C., J. T. A. Dick \& R. W. Elwood, 1997. The trophic ecology of freshwater Gammarus spp. (Crustacea: Amphipoda): problems and perspectives concerning the functional feeding group concept. Biological Reviews of the Cambridge Philosophical Society 72: 349-364.

Mathers, K. L. \& P. J. Wood, 2016. Fine sediment deposition and interstitial flow effects on macroinvertebrate community composition within riffle heads and tails. Hydrobiologia 776: 147-160.

Mathers, K. L., J. Millett, A. L. Robertson, R. Stubbington \& P. J. Wood, 2014. Faunal response to benthic and hyporheic sedimentation varies with direction of vertical hydrological exchange. Freshwater Biology 59: 2278-2289.

Mathers, K. L., S. P. Rice \& P. J. Wood, 2017. Temporal effects of enhanced fine sediment loading on macroinvertebrate community structure and functional traits. Science of the Total Environment 599: 513-522. 
McGrath, K. E., E. T. H. M. Peeters, J. A. J. Beijer \& M. Scheffer, 2007. Habitat-mediated cannibalism and microhabitat restriction in the stream invertebrate Gammarus pulex. Hydrobiologia 589: 155-164.

McManamay, R. A., D. J. Orth, C. A. Dolloff \& M. A. Cantrell, 2010. Gravel addition as a habitat restoration technique for tailwaters. North American Journal of Fisheries Management 30: 1238-1257.

Merz, J. E. \& L. K. Ochikubo Chan, 2005. Effects of gravel augmentation on macro-invertebrate assemblages in a regulated Californian river. River Research \& Applications 21: 61-74.

Michel, C., Y. Schindler Wildhaber, J. Epting, K. L. Thorpe, P. Huggenberger, C. Alewell \& P. Burkhardt-Holm, 2014. Artificial steps mitigate the effect of fine sediment on the survival of brown trout embryos in a heavily modified river. Freshwater Biology 59: 544-556.

Naden, P. S., J. F. Murphy, G. H. Old, J. Newman, P. Scarlett, M. Harman, C. P. Duerdoth, A. Hawczak, J. L. Pretty, A. Arnold, C. Laizé, D. D. Hornby, A. L. Collins, D. A. Sear \& J. I. Jones, 2016. Understanding the controls on deposited fine sediment in the streams of agricultural catchments. Science of the Total Environment 547: 366-381.

Navel, S., F. Mermillod-Blondin, B. Montuelle, E. Chauvet, L. Simon, C. Piscart \& P. Marmonier, 2010. Interactions between fauna and sediment control the breakdown of plant matter in river sediments. Freshwater Biology 55: 753-766.

Nogaro, G., F. Mermillod-Blondin, F. François-Carcaillet, J. P. Gaudet, M. LaFont \& J. Gibert, 2006. Invertebrate bioturbation can reduce the clogging of sediment: an experimental study using infiltration sediment columns. Freshwater Biology 51: 1458-1473.

Nogaro, G., F. Mermillod-Blondin, B. Montuelle, J. C. Boisson \& J. Gibert, 2008. Chironomide larvae stimulate biogeochemical and microbial processes in a riverbed covered with fine sediment. Aquatic Sciences 70: 160-169.

Olsen, D. A. \& C. R. Townsend, 2003. Hyporheic community composition in a gravel-bed stream: influence of vertical hydrological exchange, sediment structure and physiochemistry. Freshwater Biology 48: 1363-1378.

Palm, D., E. Brännäs, F. Lepori, K. Nillsson \& S. Stridsman, 2007. The influence of spawning habitat restoration on juvenile brown trout (Salmo trutta) density. Canadian Journal of Fisheries and Aquatic Sciences 64: 509-515.

Pyne, M. I. \& N. L. Poff, 2017. Vulnerability of stream community composition and function of projected thermal warming and hydrologic change across ecoregions in the western United States. Global Change Biology 23: 77-93.

Richards, C. \& K. L. Bacon, 1994. Influence of fine sediment on macroinvertebrate colonization of surface and hyporheic stream substrates. Great Basin Naturalist 54: 106-113.

Strachan, S. R., E. T. Chester \& B. J. Robson, 2015. Freshwater invertebrate life history strategies for surviving desiccation. Springer Science Reviews 3: 57-75.

Stubbington, R., 2012. The hyporheic zone as an invertebrate refuge: a review of variability in space, time, taxa and behaviour. Marine and Freshwater Research 63: 293-311.
Stubbington, R., J. Gunn, S. Little, T. P. Worrall \& P. J. Wood, 2016. Macroinvertebrate seedbank composition in relation to antecedent duration of drying and multiple wet-dry cycles in a temporary stream. Freshwater Biology 61: 1293-1307.

Stumpp, C. \& G. C. Hose, 2013. The impact of water table drawdown and drying on subterranean aquatic fauna in in vitro experiments. PLoS one 8: e78502.

Stumpp, C. \& G. C. Hose, 2017. Groundwater amphipods alter aquifer sediment structure. Hydrological Processes 31: 3452-5454.

Taylor, K. G. \& P. N. Owens, 2009. Sediments in urban river basins: a review of sediment-contaminant dynamics in an environmental system conditioned by human activities. Journal of Soils and Sediments 9: 281-303.

Vadher, A. N., R. Stubbington \& P. J. Wood, 2015. Fine sediment reduces vertical migrations of Gammarus pulex (Crustacea: Amphipoda) in response to surface water loss. Hydrobiologia 753: 61-71.

Vadher, A. N., C. Leigh, J. Millett, R. Stubbington \& P. J. Wood, 2017. Vertical movements through subsurface stream sediments by benthic macroinvertebrates during experimental drying are influenced by sediment characteristics and species traits. Freshwater Biology 62: 1730-1740.

Vander Vorste, R., F. Malard \& T. Datry, 2016a. Is drift the primary process promoting the resilience of river invertebrate communities? A manipulative field experiment in an intermittent alluvial river. Freshwater Biology 61: 1276-1292.

Vander Vorste, R., F. Mermillod-Blondin, F. Hervant, R. Mons, M. Forcellini \& T. Datry, 2016b. Increased depth to the water table during river drying decreases the resilience of Gammarus pulex and alters ecosystem function. Ecohydrology 9: 1177-1186.

van Vliet, M. T. H. \& J. J. G. Zwolsman, 2008. Impact of summer droughts on the water quality of the Meuse River. Journal of Hydrology 353: 1-17.

Verdonschot, R. C. M., A. M. van Oosten-Siedlecka, C. J. F. ter Braak \& P. F. M. Verdonschot, 2015. Macroinvertebrate survival during cessation of flow and streambed drying in a lowland stream. Freshwater Biology 60: 282-296.

Verstraeten, G. \& J. Poesen, 2000. Estimating trap efficiency of small reservoirs and ponds: methods and implications for the assessment of sediment yield. Progress in Physical Geography 24: 219-251.

Weigelhofer, G. \& J. Waringer, 2003. Vertical distribution of benthic macroinvertebrates in riffles versus deep runs with differing contents of fine sediments (Weidlingbach, Austria). International Review of Hydrobiology 88: 304-313.

Wood, P. J. \& P. D. Armitage, 1997. Biological effects of fine sediment in the lotic environment. Environmental Management 21: 203-217.

Wood, P. J., J. Gunn \& S. D. Rundle, 2008. Response of benthic cave invertebrates to organic pollution events. Aquatic Conservation 18: 909-922.

Wood, P. J., A. J. Boulton, S. Little \& R. Stubbington, 2010. Is the hyporheic zone a refugium for aquatic macroinvertebrates during severe low flow conditions? Fundamental and Applied Limnology 176: 377-390. 